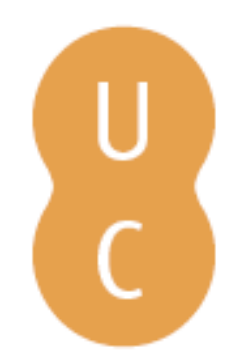

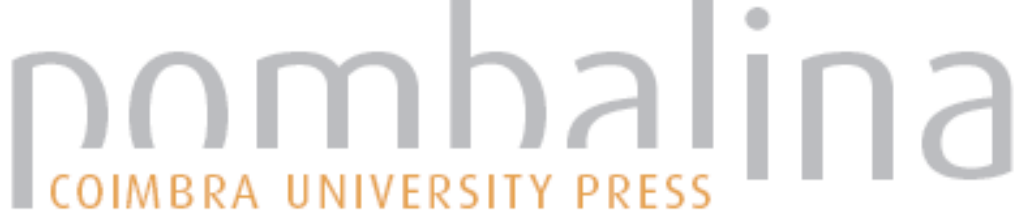

\section{Reabilitação profissional de pessoas com doença mental: o estado da arte}

Autor(es): $\quad$ Teixeira, Carina; Santos, Eduardo; Abreu, Manuel Viegas

Publicado por: Imprensa da Universidade de Coimbra

URL

persistente:

URI:http://hdl.handle.net/10316.2/35956

DOI:

DOI:http://dx.doi.org/10.14195/978-989-26-0852-5_3

Accessed : $\quad$ 26-Apr-2023 11:20:31

A navegação consulta e descarregamento dos títulos inseridos nas Bibliotecas Digitais UC Digitalis, UC Pombalina e UC Impactum, pressupõem a aceitação plena e sem reservas dos Termos e Condições de Uso destas Bibliotecas Digitais, disponíveis em https://digitalis.uc.pt/pt-pt/termos.

Conforme exposto nos referidos Termos e Condições de Uso, o descarregamento de títulos de acesso restrito requer uma licença válida de autorização devendo o utilizador aceder ao(s) documento(s) a partir de um endereço de IP da instituição detentora da supramencionada licença.

Ao utilizador é apenas permitido o descarregamento para uso pessoal, pelo que o emprego do(s) título(s) descarregado(s) para outro fim, designadamente comercial, carece de autorização do respetivo autor ou editor da obra.

Na medida em que todas as obras da UC Digitalis se encontram protegidas pelo Código do Direito de Autor e Direitos Conexos e demais legislação aplicável, toda a cópia, parcial ou total, deste documento, nos casos em que é legalmente admitida, deverá conter ou fazer-se acompanhar por este aviso. 

Carina Teixeira ${ }^{1-2}$, Eduardo Santos ${ }^{1-2}$, Manuel Viegas Abreu ${ }^{1-2}$.

\section{REABILITAÇÃO PROFISSIONAL DE PESSOAS COM DOENÇA MENTAL: O ESTADO DA ARTE}

Alarguei os meus horizontes. Estou diariamente a ganhar confiança e alguma segurança a nível financeiro - não é muito, mas estou a ganhar qualquer coisa. Peguei no meu primeiro cheque-ordenado - foi o meu primeiro em sete anos - e emoldurei-o. Fotocopiei-o porque tinha de o depositar, mas pus a cópia numa moldura em minha casa. Depois preenchi um cheque pessoal e coloquei-o numa moldura mais pequena. Sinto-me ligado à sociedade porque trabalho. Estou a fazer amigos, por isso o meu isolamento é agora limitado. Posso isolar-me durante um fim-de-semana, mas é mais ou menos como um período de recuperação (testemunho de um doente cit. in Leff e Warner, 2008, p. 161)

\section{Emprego Protegido}

O programa de emprego protegido diz respeito ao exercício de uma actividade remunerada em oficinas criadas especificamente para pessoas com determinado tipo de incapacidade, estando os participantes, tal como o nome indica, protegidos dos requisitos de produtividade do mercado competitivo.

\footnotetext{
${ }^{1}$ Instituto de Psicologia Cognitiva, Desenvolvimento Vocacional e Social da Universidade de Coimbra.

2 Associação ReCriar Caminhos - Associação de Apoio ao Desenvolvimento Vocacional, Formação e Inclusão de Pessoas com Esquizofrenia. E-mail: carina_psi@hotmail.com
} 
O emprego protegido tem perdido popularidade, visto que os estudos mostram que este programa não leva aos mesmos benefícios não vocacionais - tais como melhor controlo dos sintomas, aumento da auto-estima e melhoria na qualidade de vida - do emprego competitivo (Bond et al., 2001). Bond e colaboradores (2001) examinaram os efeitos cumulativos do trabalho nos sintomas, qualidade de vida e auto-estima de 149 pessoas com doença mental severa desempregadas que recebiam reabilitação profissional. As medidas não vocacionais foram avaliadas em intervalos de 6 meses durante o período de estudo de 18 meses, e a actividade profissional foi monitorizada continuamente. Com base na sua actividade durante o período de estudo, os participantes foram classificados em quatro grupos: trabalho competitivo, trabalho protegido, trabalho mínimo e sem trabalho. Os grupos não diferiam na linha de base em qualquer das medidas não vocacionais. Os autores verificaram que o grupo em emprego competitivo mostrou resultados mais elevados em termos de melhorias nos sintomas, satisfação com os serviços vocacionais, lazer, finanças e auto-estima, do que os participantes de um grupo que incluía pessoas em trabalho mínimo e pessoas sem trabalho. O grupo de trabalho protegido não mostrou essa vantagem.

O trabalho é benéfico quando proporciona um veículo para o desenvolvimento da criatividade, sendo que a maior parte do trabalho em emprego protegido não está desenhado para corresponder a esta necessidade (Moreton, 1992). Além disso, os pacientes deveriam ser avaliados para determinar quer as suas limitações, quer as suas potencialidades, no sentido de se criar um programa adequado às suas idiossincrasias. $\mathrm{Na}$ prática, isto raramente acontece e as oficinas protegidas muitas vezes persistem com a abordagem de tratamento em bloco que caracteriza os programas institucionais (Leff, 2008). No entanto, os defensores do emprego protegido apontam que para algumas pessoas com capacidade de funcionamento limitada, os serviços protegidos podem ser o único programa adequado.

Para abordar algumas das preocupações dos críticos, é possível reestruturar as oficinas protegidas, de modo a se assemelharem às empresas 
sociais $^{3}$. O envolvimento dos trabalhadores no planeamento dos negócios tem potencial de aumentar os benefícios não vocacionais do trabalho (Leff e Warner, 2008).

\section{Emprego Apoiado}

Lehman fez, em 1995, uma revisão da investigação sobre os resultados da reabilitação profissional para pessoas com esquizofrenia durante a era da desinstitucionalização, concluindo que a maioria dos programas de reabilitação profissional tinham uma influência positiva nas actividades relacionadas com o trabalho, mas não demonstravam, contudo, impactos duradouros e substanciais no emprego competitivo. O emprego apoiado foi o primeiro programa efectivo na colocação de pessoas com doença mental no mercado de trabalho competitivo.

De uma forma geral, podemos caracterizar este programa da seguinte maneira: no início da colocação, a pessoa com doença mental é totalmente apoiada por um técnico, sendo que à medida que o trabalhador adquire as competências necessárias e ganha confiança na sua capacidade para desempenhar tarefas, o apoio é gradualmente retirado e fornecido a outro paciente. As competências e preferências dos indivíduos podem ser consolidadas seleccionando um emprego apropriado, e é possível a progressão para postos melhor remunerados (Leff, 2008).

O emprego apoiado para pessoas com doença mental severa é uma prática baseada na evidência, fundamentada em resultados convergentes de estudos de conversão de tratamento em hospital de dia em emprego apoiado e em estudos controlados aleatoriamente, comparando o programa de emprego apoiado com uma variedade de abordagens alternativas. Estas linhas de investigação sugerem que entre $40 \%$ a $60 \%$ dos pacientes envolvidos em emprego apoiado obtêm emprego competitivo. Por outro lado, menos de $20 \%$ de pacientes similares atingem o mercado normal quando não envolvidos em emprego apoiado (Bond, 2004). Bond e Drake

\footnotetext{
3 Ver ponto 3 .
} 
(2008) verificaram, no seu trabalho de revisão, que o emprego apoiado é o preditor mais forte na obtenção de emprego competitivo.

No entanto, as trajectórias a longo prazo de participantes em emprego apoiado não têm sido claras. Becker, Whitley, Bailey e Drake (2007) realizaram um estudo exploratório acerca das trajectórias de adultos com incapacidade psiquiátrica que participaram em emprego apoiado. Becker e colaboradores (2007) voltaram a entrevistar 38 de 78 participantes com doença mental severa, oito a doze anos após se terem envolvido em emprego apoiado. No período de follow-up, a grande maioria (82\%) trabalhava em emprego competitivo. Os participantes reportaram numerosos benefícios relacionados com o emprego, incluindo melhorias na auto-estima, relações interpessoais e controlo da doença.

Bond (2004) refere que o programa de colocação e apoio individuais, amplamente estudado nos últimos anos, constitui uma estandardização dos princípios do emprego apoiado, de modo a que este possa ser claramente descrito, cientificamente estudado e implementado em novas comunidades. Bond $(1998 ; 2004)$ sublinhou muitos princípios desta abordagem: 1. Elegibilidade baseada na escolha da pessoa em reabilitação; 2. Integração da reabilitação vocacional nos serviços de saúde mental; 3. Serviços Focados em Emprego Competitivo; 4. Procura rápida de emprego e colocação; 5. Atenção às preferências da pessoa com doença mental; 6. Avaliação e Apoio Contínuos; 7. O planeamento personalizado de benefícios.

\section{Empresas Sociais}

Uma alternativa à competitividade no mercado de trabalho consiste em criar empresas geridas pelos pacientes, cumprindo, deste modo, uma dupla missão - criar um produto ou serviço necessário e empregar pessoas em situação de desvantagem (Leff \& Warner, 2008; Warner \& Mandiberg, 2006).

Estas oportunidades vocacionais não procuram criar um ambiente artificialmente protegido, mas possibilitar aos pacientes psiquiátricos com formação profissional o envolvimento em actividades economicamente 
eficazes (World Health Organization [WHO], 2001). As empresas sociais operam em mercado aberto em competição com empresas públicas e privadas (Leff, 2008).

As empresas sociais foram pioneiras em Itália na década de 70 do século passado e surgiram como resposta ao programa de desinstitucionalização, o qual levou à proibição de admissões em hospitais psiquiátricos por todo o país (Leff, 2008). A lei 180 promulgada em Itália em 1978, fechando todos os hospitais psiquiátricos, formalizou e acelerou uma tendência pré-existente nos cuidados das pessoas com doença mental (WHO, 2001). A primeira empresa para pacientes psiquiátricos foi criada em Trieste em 1973 durante a desinstitucionalização do Hospital de San Giovanni e prestava serviços na área da limpeza. Em 1994, o consórcio em Trieste expandiu para incluir um hotel, um café, um restaurante, uma empresa de transportes e uma companhia de restauração de edifícios (Leff, 2008; Warner \& Mandiberg, 2006).

Os princípios pelos quais se regem as empresas sociais incluem os seguintes: mais de um terço dos trabalhadores são pessoas com incapacidade; todos os trabalhadores são remunerados com um salário de mercado adequado ao emprego, independentemente da sua capacidade de produção; e estabelece os mesmos direitos, oportunidades e obrigações para todos os funcionários (Leff \& Warner, 2008). De salientar que a empresa funciona sem subsídios. As empresas que recebem subsídios podem ser consideradas empresas sociais “emergentes" (Warner \& Mandiberg, 2006).

O número de empresas sociais tem aumentado significativamente nos últimos anos. No seu relatório de 2001, a Organização Mundial de Saúde indicou que, na Europa, cerca de 10000 indivíduos com doença mental se encontravam a trabalhar em empresas sociais (WHO, 2001). Em 2005, já existiam mais de 8000 empresas sociais na Europa com 80000 trabalhadores, 30000 dos quais com incapacidades (Warner \& Mandiberg, 2006).

Warner e Mandiberg publicaram em 2006 um artigo sobre o ponto da situação das empresas sociais em todo o mundo. Vejamos, então, de seguida, alguns dados do trabalho dos autores. O maior número de empresas sociais fora da Itália situa-se na Alemanha, existindo em 2005 mais de 500 empresas deste tipo. No Reino Unido, havia, antes de 1997, 
apenas 6 empresas sociais. Desde então, com a ajuda do grupo de apoio às Empresas Sociais no Reino Unido, o número cresceu para 49 empresas sociais e 70 empresas sociais emergentes. A assistência técnica da Itália e da Alemanha promoveu este crescimento. Em 2005, as empresas sociais britânicas empregavam mais de 1500 pessoas, dois terços com incapacidades, maioritariamente incapacidades mentais. Na Ásia do leste e na América do Norte, as empresas sociais desenvolveram-se independentemente e não por difusão do modelo Europeu. Na Coreia, as empresas sociais foram criadas por modificação do modelo ocidental das oficinas protegidas. Ao contrário das oficinas protegidas, os recursos humanos incluem trabalhadores com e sem incapacidades, e todos os trabalhadores são pagos à hora em vez de à peça. No Canadá, a maior parte dos programas vocacionais para pessoas com doença mental foram convertidos em empresas sociais. Quanto aos Estados Unidos, embora existam organizações de apoio às empresas sociais, como por exemplo a Social Enterprise Alliance e a Workability Americas, o movimento não alcançou a vitalidade vista em partes da Europa e mesmo no Canadá. O fraco crescimento das empresas sociais nos Estados Unidos pode ser devido, em parte, ao sucesso do emprego apoiado.

Um exemplo africano do modelo de empresa social situa-se em Bouaké, Costa do Marfim, onde foi criada uma quinta de criação de galinhas para empregar pessoas com doença mental, algumas das quais institucionalizadas durante anos. Inicialmente vista como suspeita pela população local, a quinta rapidamente cresceu, tornando-se uma importante empresa da qual a comunidade agora depende. A resistência inicial foi gradualmente transformada em apoio, particularmente quando a quinta teve falta de trabalhadores e começou a contratar pessoas da comunidade local, tornando-se o maior empregador da área (WHO, 2001).

Estas empresas apresentam um certo número de vantagens relativamente aos programas de emprego protegido e apoiado. Cada projecto oferece uma variedade de postos de trabalho com níveis diferentes de responsabilidade e diferentes exigências de capacidade de iniciativa. Trata-se de um benefício para os pacientes de nível educacional mais elevado, susceptíveis de desempenhar uma actividade administrativa, 
ou pelo menos executar tarefas mais variadas e estimulantes (Leff \& Trieman, 2000).

Warner e Mandiberg (2006) apontam que as políticas governamentais, legislação e estatutos que favorecem as pessoas com incapacidades são essenciais para o sucesso das empresas sociais. Em Itália, a legislação prevê vantagens em relação aos impostos para as cooperativas de trabalhadores. Nos Estados Unidos, a lei Javits-Wagner-O'Day de 1971 (Warner \& Mandiberg, 2006) encoraja as entidades governamentais a usar produtos e serviços das empresas sociais.

O sucesso das empresas sociais pode ser reforçado pelos seguintes factores: localizar o melhor nicho de mercado ${ }^{4}$; seleccionar opções de negócio que requerem trabalho intensivo, de modo a maximizar as possibilidades de emprego com o mínimo investimento de capital (por exemplo, serviços de limpeza e reparação ou produtos manufacturados); ter uma orientação pública para o negócio 5 e estabelecer ligação com os serviços de tratamento (Warner \& Mandiberg, 2006).

Em Portugal, as empresas sociais são designadas de empresas de inserção. A portaria 348-A/98 cria as empresas de inserção no âmbito do Mercado Social de Emprego: "Das empresas de inserção se podem esperar efeitos de promoção das condições de empregabilidade de pessoas pertencentes aos grupos mais desfavorecidos face ao mercado de trabalho, através da profissionalização, da aquisição de um currículo profissional, de hábitos de trabalho em organização, de elevação de auto-confiança e melhoria da imagem dessas pessoas". São destinatários da medida

\footnotetext{
${ }^{4}$ Muitas destas empresas conseguiram uma posição favorável no mercado através de contratos com instituições públicas. Estas instituições (por exemplo, hospitais) têm, geralmente, uma preocupação especial para com a exclusão social de pessoas com incapacidades (Leff \& Warner, 2008).

5 A orientação pública de uma empresa social pode ser uma vantagem na obtenção de contratos através de uma vontade de combater os problemas da comunidade. Vejamos o seguinte exemplo: os administradores de um grupo de Cooperativas em Trieste, Itália, reuniram-se com as autoridades locais para discussão de problemas existentes na comunidade. Um problema significativo era o número de motas avariadas e abandonadas nas ruas. Consequentemente, foi estabelecido um plano para a criação de uma oficina de reparação de motas, cujos funcionários seriam jovens desfavorecidos, muitos deles com historial de desmontagem de motas nas ruas para roubar as peças (Leff \& Warner, 2008; Warner \& Mendiberg, 2006).
} 
desempregados de longa duração inscritos nos centros de emprego e os desempregados em situação de desfavorecimento face ao mercado de trabalho, incluindo, portanto, as pessoas com perturbações psiquiátricas em processo de recuperação.

As empresas de inserção organizam-se e funcionam segundo modelos de gestão empresarial, com as adaptações exigidas pelos fins que prosseguem, tomando as providências necessárias relativas à adaptação dos postos de trabalho, consoante as características dos trabalhadores em processo de inserção.

\section{Discussão e Conclusão}

A reabilitação profissional tem assumido uma importância cada vez maior como parte do espectro de cuidados para pessoas com esquizofrenia. À excepção do emprego apoiado, o número de estudos controlados acerca de programas de reabilitação profissional é pequeno. Os potenciais benefícios terapêuticos da reabilitação profissional, além de um melhor desempenho no trabalho, precisam de ser explorados. De particular interesse são os impactos na sintomatologia clínica, auto-estima, qualidade de vida e adesão ao tratamento.

Tendo em conta o estado da arte, o IPCDVS pretende em investigação futura responder às seguintes questões: Será o trabalho clinicamente benéfico para as pessoas com doença mental de evolução prolongada? Qual o impacto do trabalho no funcionamento, auto-estima e qualidade de vida dos doentes com esquizofrenia? Quais são os custos e os benefícios para a sociedade do trabalho de pessoas com problemas de saúde mental? As intervenções de reabilitação profissional aumentam os resultados vocacionais e não vocacionais das pessoas com esquizofrenia? Há diferenças na efectividade dos vários tipos de programas de reabilitação profissional para pessoas com esquizofrenia? Que características dos pacientes predizem a resposta à reabilitação profissional? O IPCDVS pretende, ainda, avaliar em que medida os programas precisam de ser adaptados aos diferentes diagnósticos incluídos na categoria heterogénea "doença mental severa". 
Assim, grupos mais homogéneos de pacientes devem ser estudados para reduzir o impacto da heterogeneidade da amostra no poder de detectar o impacto do programa. Por fim, e tendo em conta a evidência consistente e forte, demonstrada no estado da arte, da efectividade do emprego apoiado em ajudar os indivíduos com esquizofrenia a alcançar o emprego competitivo, o Plano Nacional de Saúde Mental deveria tornar o acesso a esta prática uma prioridade elevada. A experiência de Itália e de outros países mostra que a criação de empresas sociais é também uma resposta efectiva na inserção profissional de pessoas com doença mental.

Em suma, reiteramos a ideia de que o trabalho não proporciona apenas uma remuneração financeira, mas também, e sobretudo, uma experiência de normalização, permitindo aos indivíduos com doença mental severa participar na sociedade através do desempenho de um papel produtivo. Não restam dúvidas que desempenhar um papel produtivo, além de melhorar a evolução da doença (o que leva à diminuição dos custos do tratamento), traz um sentido de rumo e significado à vida. A ReCriar Caminhos, Associação fundada em 2008 pelos autores deste artigo, tendo por missão o apoio ao desenvolvimento vocacional, formação e inclusão de pessoas com esquizofrenia e verificando as experiências de sucesso noutras partes do mundo, pretende implementar estes diferentes programas, tentando devolver, deste modo, à sua população alvo, um papel social com significado.

\section{Referências bibliográficas}

BeCKer, D., Whitley, R., BAILEy, E. L. \& DRAKE, R. E. (2007). Long-term employment trajectories among participants with severe mental illness. Psychiatric Services, 58 (7), 922-928.

BOND, G. R. (1998). Principles of the Individual Placement and Support model: Empirical support. Psychiatric Rehabilitation Journal, 22, 11-23.

BOND, G. R. (2004). Supported employment: evidence for an evidence-based practice. Psychiatric Rebabilitation Journal, 27, 345-359.

BOND, G. R. \& DRAKE, R. (2008). Predictors of competitive employment among patients with schizophrenia. Current Opinion in Psychiatry, 21 (4), 362-369. 
Bond, G. R., Resnick, S. G., DRAKe, R. E., Xie, H., MCHugO, G. J. \& Bebout, R. R. (2001). Does competitive employment improve nonvocational outcomes for people with severe mental illness? Journal of Consulting and Clinical Psychology, 69 (3), 489-501.

LEFF, J. (2008). Inclusão social de pessoas com doença mental: a importância do trabalho. In M. V. Abreu \& E. R. Santos (Coord.). O Papel das Famílias e das Redes de Apoio Social - Actas do Primeiro Congresso de Reabilitação e Inclusão na Saúde Mental (pp. 23-40). Coimbra: Edições Almedina.

LEFF, J. \& TRIEMAN, N. (2000). A criação de um serviço psiquiátrico completo na comunidade. In J. Leff (Ed.). Cuidados na comunidade: Ilusão ou realidade? (pp. 233-247). Lisboa: Climepsi Editores.

LeFF, J. \& WARner, R. (2008). Inclusão Social de Pessoas com Doenças Mentais (A. P. Lopes, Trad.). Coimbra: Edições Almedina. (Obra original publicada em 2006).

LEHMAN, A. F. (1995). Vocational rehabilitation in schizophrenia. Schizophrenia Bulletin, $21,645-656$.

MORETON, T. (1992). Sheltered Employment: Gateway or "Road Block"? University Press, $21,37-54$.

Mueser, K. T., Becker, D. R., TORrey, W. C., Xie, H., Bond G. R., DraKe, R. E. \& DAin, B. J. (1997). Work and nonvocational domains of functioning in persons with severe mental illness: a longitudinal analysis. The Journal of Nervous and Mental Disease, 185 (7), 419-26.

Portaria 348-A/98 de 18 de Junho. Diário da República $n .^{\circ} 138 / 99$ - I Série B. Ministério do Trabalho e da Solidariedade. Lisboa.

WORLD HEALTH ORGANIZATION (2001). Mental health: new understanding, new hope. Geneva: Author.

WARNER, R. \& MANDIBERG, J. (2006). An update on affirmative business or social firms for people with mental illness. Psychiatric Services, 57 (10), 1488-1492. 